\title{
Correction to: Practising an explosive eruption in Iceland: outcomes from a European exercise
}

Claire Witham ${ }^{1 *}$, Sara Barsotti ${ }^{2}$, Stéphanie Dumont ${ }^{3,4,5}$, Björn Oddsson ${ }^{6}$ and Freysteinn Sigmundsson ${ }^{3}$

Correction to: Journal of Applied Volcanology (2020) 9:1

https://doi.org/10.1186/s13617-019-0091-7

In the publication of this article [1], there was an error in the copyright holder name. The error: () The Author(s) should instead read (c) Crown. The original article has been corrected.

\footnotetext{
Author details

${ }^{1}$ Met Office, FitzRoy Road, Exeter EX1 3PB, UK. ${ }^{2}$ Icelandic Meteorological Office, Bústaðavegur 7-9, 108 Reykjavík, Iceland. ${ }^{3}$ Nordic Volcanological Center, Institute of Earth Sciences, University of Iceland, Sturlugata 7, 101 Reykjavík, Iceland. ${ }^{4}$ University of Beira Interior, Covilhã, Portugal. ${ }^{5}$ Instituto Dom Luiz (IDL), Faculdade de Ciências da Universidade de Lisboa, Lisbon Portugal. ${ }^{6}$ National Commissioner of Icelandic Police, Ríkislögreglustjórinn, Skúlagata 21, 101 Reykjavík, Iceland.
}

Published online: 18 February 2020

\section{Reference}

1. Witham C, Barsotti S, Dumont S et al (2020) Practising an explosive eruption

in Iceland: outcomes from a European exercise. J Appl Volcanol 9:1

https://doi.org/10.1186/s13617-019-0091-7

* Correspondence: claire.witham@metoffice.gov.uk

${ }^{1}$ Met Office, FitzRoy Road, Exeter EX1 3PB, UK

Full list of author information is available at the end of the article 